\title{
From our readers
}

To the editor - The paper Electronically conductive phospho-olivines as lithium storage electrodes by Chung et al., published in the second issue of this journal ${ }^{1}$, suggests that the electrode material, $\mathrm{LiFePO}_{4}$, can be doped to reach high electronic conductivity values.

This would alleviate the need for the use of carbon as a thin coating, or as an admixture in large amounts of ultrafine powder, in order to reach its electrochemical capacity. We suggest that the effects seen by Chung et al. are due to carbon for low-temperature samples, and to low-valency iron derivatives imparting semimetallic conductivity in samples treated above $750{ }^{\circ} \mathrm{C}$.

This mixed lithium-iron phosphate is highly ionic (gap $>4 \mathrm{eV}$ ), with a large electron effective mass. Contrary to spinels, the olivine structure is unfavourable to aliovalent doping. The instability of the non-stoichiometric compound $\mathrm{Li}_{1-x} \mathrm{Fe}_{1-x}^{\mathrm{II}} \mathrm{Fe}^{\mathrm{III}} \mathrm{PO}_{4} \Rightarrow x \mathrm{Fe}^{\mathrm{III}} \mathrm{PO}_{4}+$ $(1-x) \mathrm{LiFe}^{\mathrm{II}} \mathrm{PO}_{4}$ (battery operation) suggests that the $\mathrm{M} 1$ sites accept negligible vacancy concentration ${ }^{2}$. Our attempted substitution of $\left(\mathrm{Fe}^{\mathrm{III}}+\mathrm{Li}^{\mathrm{I}}\right)$ for two $\mathrm{Fe}^{\mathrm{II}}$ on $\mathrm{M} 2$ sites resulted in a disproportionation: $\mathrm{Li}_{(1+x)} \mathrm{Fe}^{\mathrm{II}}{ }_{(1-2 x)} \mathrm{Fe}^{\mathrm{III}}{ }_{x} \mathrm{PO}_{4} \Rightarrow$ $x \mathrm{Fe}^{\mathrm{III}} \mathrm{PO}_{4}+(1-2 x) \mathrm{LiFe}^{\mathrm{II}} \mathrm{PO}_{4}+x \mathrm{Li}_{3} \mathrm{PO}_{4}$. It is thus unlikely that dopants on either M1 or M2 sites with charges varying from +1 to +5 could: i) dissolve in the lattice; ii) create vacancies; or iii) induce high conductivity, especially if the $\mathrm{Fe}^{\mathrm{III}}$ environment differs from that of $\mathrm{Fe}^{\mathrm{II}}$ (ref. 2). It is beyond, not the scope, but the length of this letter to discuss the juggling of point defect chemistry equations to justify the results, especially for a two-phase system! Focusing on reproducibility, we synthesised $\mathrm{Li}_{0.99} \mathrm{M}_{0.01} \mathrm{FePO}_{4}$ following the procedures by Chung et al., using the same precursors. Two sets of samples were ball-milled in stainless steel (identical results with porcelain) or polypropylene containers, the latter a known source of organic contamination.

Conductivities were measured on powders obtained from pellets $\left(800^{\circ} \mathrm{C}\right.$ for 4 hours $)$, from the resistance value measured under 1 ton pressure. This was judged more reproducible, as carbon hinders sintering. Slow-scan voltammetry $\left(20 \mathrm{mVh}^{-1}\right.$; VMP, Biologic, Claix, France), less dependant on the experimental set-up (geometry, quality of interfaces ...), was used for electrochemical tests to determine the capacity of the material. Table I summarizes the results for $\mathrm{M}=\mathrm{Zr}$ and $\mathrm{Nb}$.

Unambiguously, it is the polyolefin worn from jars, subsequently charred into carbon, which is responsible for the good use of the $\mathrm{LiFePO}_{4}$ electrode. The best high-rate capacities were obtained for the niobiumdoped sample (2.3\% carbon) of $103 \mathrm{mAh} \mathrm{g}^{-1}$

\begin{tabular}{|c|c|c|c|c|c|}
\hline Doping agent & Source & $\begin{array}{c}\text { Milling } \\
\text { container }\end{array}$ & $\begin{array}{l}\mathrm{C} \\
(\%)\end{array}$ & $\begin{array}{l}\text { Conductivity at } \\
\text { room temperature } \\
\left(\mathrm{S} \mathrm{cm}^{-1}\right)\end{array}$ & $\%$ Capacity \\
\hline $\mathrm{Zr}^{4+}$ & $\mathrm{Zr}\left(\mathrm{OC}_{2} \mathrm{H}_{5}\right)_{4}$ & $\begin{array}{c}\text { SS } \\
\text { PE/PP }\end{array}$ & $\begin{array}{l}0.25 \\
0.90\end{array}$ & $\begin{array}{l}5.310^{-9} \\
5.010^{-7}\end{array}$ & $\begin{array}{l}38.4 \\
57.8\end{array}$ \\
\hline $\mathrm{Nb}^{5+}$ & $\mathrm{Nb}\left(\mathrm{OC}_{6} \mathrm{H}_{5}\right)_{5}$ & $\begin{array}{c}\text { SS } \\
\text { PE/PP }\end{array}$ & $\begin{array}{l}0.14 \\
2.30\end{array}$ & $\begin{array}{l}2.410^{-9} \\
9.910^{-4}\end{array}$ & $\begin{array}{l}50.4 \\
87.0\end{array}$ \\
\hline Pristine & & $\begin{array}{c}\text { SS } \\
\text { PE/PP }\end{array}$ & $\begin{array}{l}0.16 \\
2.00\end{array}$ & $\begin{array}{l}2.0 .10^{-8} \\
2.810^{-4}\end{array}$ & $\begin{array}{l}48.0 \\
84.9\end{array}$ \\
\hline
\end{tabular}

at $4 \mathrm{C}$ (nominal capacity in $1 / 4 \mathrm{~h}$ ), and was only $21 \mathrm{mAh} \mathrm{g}^{-1}$ for $0.3 \%$ carbon.

From this, we may conclude that the 'doping effect' giving this level of conductivity - yet to be proven - is masked by the 'carbon effect', from whatever source, responsible for both the conductivity and the electrochemical activity. Even if there is no extraneous carbon, difficult to achieve considering the ubiquity of organic contamination (seals, plasticizers from plastic tubing ...), the oxalate itself is a source of carbon - though less controllable than the pyrolysis of polymers as it depends on the heating rate - from the

disproportionation of $\mathrm{CO}$ catalysed by Fe species. Above $800^{\circ} \mathrm{C}$, thermodynamics predict that carbon will disappear, forming $\mathrm{CO}$ and other species on progressively traversing the $\mathrm{Fe}_{9}\left(\mathrm{PO}_{4}\right) \mathrm{O}_{8} / \mathrm{Fe}_{3} \mathrm{O}_{4} / \mathrm{FeO} / \mathrm{FP}_{x} /$ $\mathrm{FeC}_{\mathrm{x}}(0 \leq x \leq 1 / 3)$ equilibria (A. D. Pelton, unpublished results, Thermfacts, Canada, October, 1998). At least one of these quasimetallic conducting species $\left(+\mathrm{MoO}_{2}\right)$ is a candidate for forming a 'network', continuing the role previously devoted to carbon, inducing high conductivity in the composite. The departure from stoichiometry due to the dopant raises the iron activity, increasing the tendency for low-valency iron species formation, hence the difference from an 'undoped' sample. The presence of iron phosphide, reported by Chung et al., confirms that the samples had been submitted to oxygen pressures below $10^{-7} \mathrm{~Pa}$ at $800^{\circ} \mathrm{C}$, attainable only through the $\mathrm{C}+1 / 2 \mathrm{O}_{2} \Leftrightarrow \mathrm{CO}$ equilibrium. The only electrochemistry reported in the paper in question is for samples fired at $600{ }^{\circ} \mathrm{C}$, where carbon is present, whatever preparation procedure is used.

26 May 2003

Nathalie Ravet, Ali Abouimrane and Michel Armand*

Laboratoire International CNRS-UdM, UMR 2289, Université de Montréal, PO Box 6122, Montréal, Québec, Canada

${ }^{*}$-mail:michel.armand@umontreal.ca

\section{References}

1. Chung, S.-Y., Bloking, J. T. \& Chiang, Y.-M. Electronically conductive phospho-olivines as lithium storage electrodes. Nature Materials 1, 123-128 (2002).

2. Andersson, A. S., Kalska, B., Haggstrom, L. \& Thomas, J. O. Lithium extraction/insertion in $\mathrm{LiFePO}_{4}$ : an X-ray diffraction and Mossbauer spectroscopy study. Solid State Ionics 130, 41-52 (2000).
Chung et al replies - The 'reproduced' experiments by Ravet et al. ${ }^{1}$ have, on closer reading, clear differences in procedure from ours $^{2}$. They do not observe increased conductivity on attempted doping, and therefore attribute our results ${ }^{2}$ to a variety of conductive secondary-phase artefacts.

The effect of the milling containers that they describe was already discussed in the Methods section of our paper ${ }^{2}$. We observed up to $3 \%$ residual carbon when polypropylene was used, whereas they report 0.90-2.30\%. Repeating what is already in our paper, knowing the effects of extraneous carbon, it was only after obtaining a number of results including the preparation of insulating samples using polypropylene containers and highly conductive ones using all-ceramic equipment, the analysis by transmission electron microscopy of the powders, and the measurement of unusually good electrochemical performance, that we 